Supporting Information

\title{
Reorganization of Interfacial Water by an Amphiphilic Cationic Surfactant Promotes CO2 Reduction
}

\author{
Zhuo-Qun Zhang ${ }^{1}$, Soumyodip Banerjee ${ }^{2}$, V. Sara Thoi ${ }^{2}$, Anthony Shoji Hall ${ }^{1,2^{*}}$ \\ 1 Department of Materials Science and Engineering, Johns Hopkins University, Baltimore \\ Maryland 21218 \\ 2 Department of Chemistry, Johns Hopkins University, Baltimore Maryland 21218
}

shoji@jhu.edu 
Table of Contents

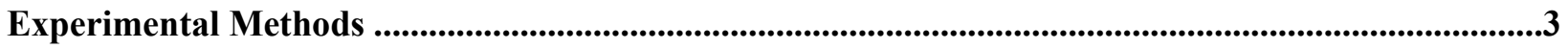

Figures

Figure S1. $\mathrm{CO}_{2}$ reduction and HER Faradaic efficiency and partial current density of $\mathrm{Cu}$ foil

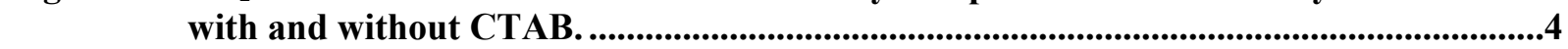

Figure S2. Product distribution on $\mathrm{Cu}$ foil with and without CTAB.....................................................5

Figure S3. Photograph and Schematic of In-situ FTIR Cell. ...........................................................5

Figure S4. Atomic force microscopy image of $\mathrm{Cu}$ evaporated onto Si wafer...................................5

Figure $\mathrm{S5}$. $\mathrm{CO}_{2}$ reduction Faradaic efficiency and partial current densities for $\mathrm{Cu}$ evaporated onto Si wafer with and without CTAB .................................................................6

Figure S6. Linear sweep and cyclic voltammograms of evaporated $\mathrm{Cu}$ on Si prism with and without CTAB.

Figure S7. Additional infrared spectra showing reproducibility............................................................

Figure S8. Infrared spectrum of solution with CTAB at 0.2 V (vs RHE) .........................................7

Figure S9. Comparison of spectra colleted in $\mathrm{NaBr}$ and $\mathrm{NaHCO}_{3}$ electrolytes ............................... 8

Figure S10. Integrated band intensity with error bars ................................................................8

Figure S11. Time dependence for v-OH absorption bands with and without CTAB.........................99

Figure S12. Potential-dependent Infrared spectra in anodic scan ................................................9

Figure S13. Adsorption profiles of $\mathrm{OH}$ and $\mathrm{OCO}$ bands in the presence of $\mathrm{NaBr} \ldots . . . . . . . . . . . . . . . . . . .10$

Figure S14. Integrated band intensity of $\mathrm{v}$-OCO with different references.....................................10

Figure S15. Time dependence for atop $\mathrm{CO}$ bands with and without CTAB.....................................10 


\section{Experimental Methods}

Copper Film Preparation: Prior to $\mathrm{Cu}$ deposition, the Si prism was polished with $1 \mu \mathrm{m}$, then $0.05 \mu \mathrm{m}$ alumina slurries respectively to clean the surface. Alumina was rinsed off with Milli-Qfiltered water $(>18.2 \mathrm{M} \Omega \mathrm{cm}$, TOC $<4 \mathrm{ppb})$ and wiped clean by Kimwipes. Then clean silicon surface was covered by $40 \mathrm{wt} \% \mathrm{NH}_{4} \mathrm{~F}$ solution via drop-casting for several minutes to remove silicon oxide layer before deposition. 25-nm of copper was deposited at $0.01-0.02 \mathrm{~nm} / \mathrm{s}$ at a base pressure of $\sim 10^{-6}$ torr on a silicon prism (60-degree Si face-angled crystal from PIKE Technologies) using a thermal evaporator.

In-situ Surface-Enhanced Infrared Absorption Spectroscopy (SEIRAS) Measurements: The copper film coated prism was compressed tightly at the bottom of a home-made H-cell assembled with VeeMax III variable angle ATR sampling accessory from PIKE, as shown in Figure S3. 30$\mathrm{mL} 0.05 \mathrm{M} \mathrm{Na}_{2} \mathrm{CO}_{3}$ (Alfa Aeser, 99.999\%) solution purified with Chelex ( $\mathrm{pH}=6.8$ ) was saturated with $\mathrm{CO}_{2}$ (research grade $99.999 \%$, Airgas) in cathodic compartment of the cell, and anodic compartment was filled with a $10-\mathrm{mL}$ of the same solution. CTAB was added to the $\mathrm{CO}_{2}$-saturated electrolyte for experiments involving $\mathrm{CO}_{2} \mathrm{RR}$ promotion by CTAB. The SEIRAS spectra of interfacial species were recorded using a Bruker Tensor II FTIR spectrometer with a HgCdTe (MCT) detector. The spectrometer was operated at scan rate of $30 \mathrm{kHz}$. Spectra were acquired with a spectral resolution of $4 \mathrm{~cm}^{-1}$, and 32 interferograms were coadded for each spectrum. The aperture size was set for $4 \mathrm{~mm}$. All spectra were shown in absorbance units defined as $-\log \left(I / I_{0}\right)$, where $I$ and $I_{0}$ represent the sample and reference spectra. Reference spectra were collected in the same electrolyte conditions as sample spectra collections. Reference spectra were collected at 0.2 V (vs RHE) for potential-dependent measurements (Figure 1, S7-S9, S12 and S14), and 0.4 V (vs RHE) for time-dependent measurements (Figure S11 and S15). For quantitative analysis, population comparison of the interfacial species was determined by numerical integration of its IR absorbance area enclosed by a baseline passing through two proper endpoints of the area (Figure 2, 3b, 4a, S10-S11 and S13-S15). Cyclic voltammetry from $0 \mathrm{~V}$ to $0.5 \mathrm{~V}$ (vs RHE) was performed to remove surface adsorbates from previous measurements at negative voltages for $\mathrm{CO}_{2}$ reduction. In-situ Electrochemical experiments along with spectra collection were conducted using EZstatpro (NuVant Systems Inc.), a leakless $\mathrm{Ag} / \mathrm{AgCl}$ electrode (eDAQ) and a graphite-rod counter electrode (Alfa Aeser, 99.9995\%). Electrode potentials were converted to the reversible hydrogen electrode $(\mathrm{RHE})$ scale using $\mathrm{E}(\mathrm{vs} \mathrm{RHE})=\mathrm{E}(\mathrm{vs} \mathrm{Ag} / \mathrm{AgCl})+0.210+0.0591 \times \mathrm{pH}$.

Electrochemical Experiments: Electrocatalysis of $\mathrm{CO}_{2}$ reduction was performed in a home-made H-cell with Autolab PGSTAT204 (Metrohm Autolab). Cu film coated on Si wafers and copper foils were used as working electrodes. $\mathrm{Cu}$-fimls coated on $\mathrm{Si}$ were prepared as described in the $\mathrm{Cu}$ 
thin film preparation section, except it was performed on Si wafers, the samples were used as received. $\mathrm{Cu}$ foils were cleaned by electropolishing in a solution of $50 \mathrm{wt} \% \mathrm{H}_{3} \mathrm{PO}_{4}$ at $50 \mathrm{~mA} \mathrm{~cm}{ }^{-2}$ for 60 seconds. A leakless Ag/AgCl electrode (eDAQ) and a graphite-rod (Alfa Aeser, 99.9995\%) was used as reference and counter electrode. Electrode potentials were converted to the reversible hydrogen electrode $(\mathrm{RHE})$ scale using $\mathrm{E}(\mathrm{vs} \mathrm{RHE})=\mathrm{E}(\mathrm{vs} \mathrm{Ag} / \mathrm{AgCl})+0.210+0.0591 \times \mathrm{pH} .0 .05$ $\mathrm{M} \mathrm{Na}_{2} \mathrm{CO}_{3}$ (Alfa Aeser, 99.999\%) solution purified with Chelex ( $\mathrm{pH}=6.8$ ), saturated with $\mathrm{CO}_{2}$ (research grade $99.999 \%$, Airgas), was prepared for $0.1 \mathrm{M} \mathrm{NaHCO}_{3}$ electrolyte. $30-\mathrm{mL}$ electrolyte was filled in cathodic compartment, and 10-mL electrolyte in anodic compartment. Potentials were corrected for uncompensated Ohmic loss $\left(\mathrm{iR}_{\mathrm{u}}\right)$ in situ via positive feedback. CTAB was added to the $\mathrm{CO}_{2}$-saturated electrolyte for the appropriate experiments. To inhibit soap suds from forming, the gas sparging tube was placed above the solution to keep the system blanketed in $\mathrm{CO}_{2}$.

Detection of Gas and Liquid Products: Gaseous $\mathrm{CO}_{2} \mathrm{RR}$ products were analyzed by GCMSQP2010 SE from Shimadzu. This instrument is assembled with a single quadrupole mass spectrometer and a gas chromatograph (GC-2010 Plus) instrument equipped with Rt-Q-bond (ID: $0.25 \mathrm{~mm}, 8$-um thickness, 30-m length) column from Restek. The GCMS was operated at $25 \mathrm{keV}$ to allow for the detection of $\mathrm{H}_{2}$. Gas products were collected every 10 min, while $\mathrm{CO}_{2}$ was continuously sparged at a flow rate of $20 \mathrm{sccm}$. The liquid products were analyzed by Bruker 400 MHZ NMR, using DMSO as an internal standard. The $1 \mathrm{D}^{1} \mathrm{H}$ spectrum was measured via water suppression by a pre-saturation method.

Atomic Force Microscopy (AFM): The surface morphology of the copper film deposited on silicon wafer was imaged by AFM (Bruker Dimension 3100) in tapping mode.

\section{Figures}

a)

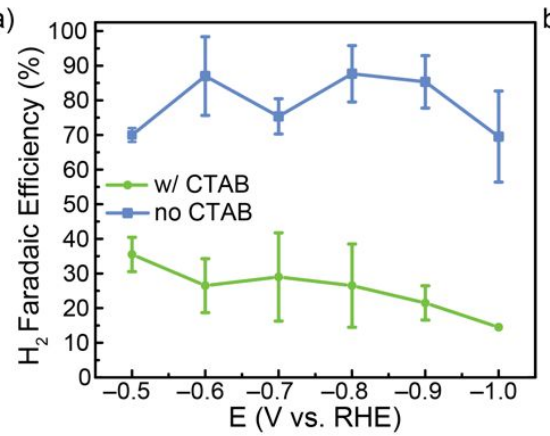

c)

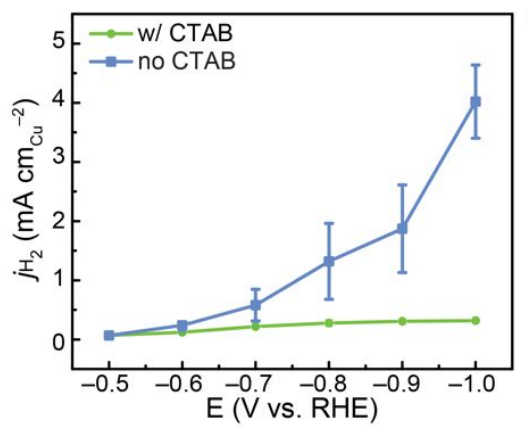

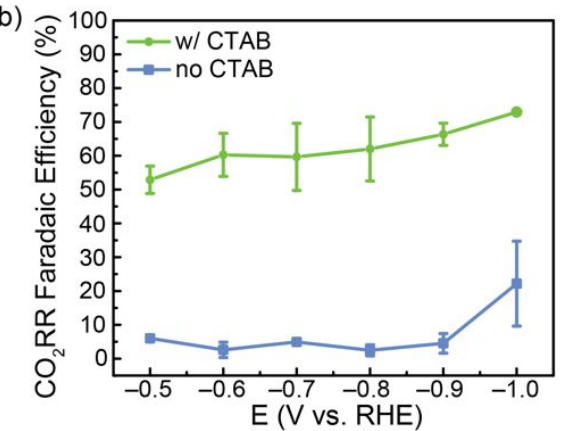

d)

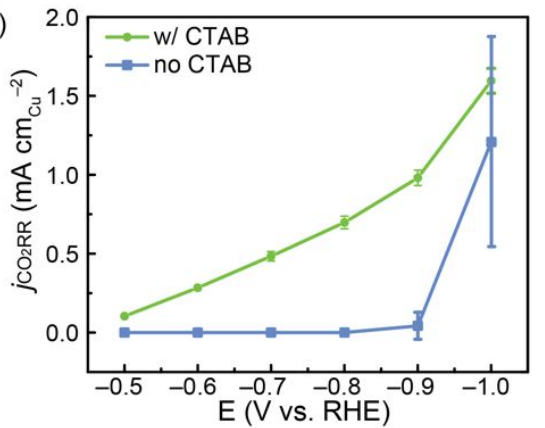

Figure S1. Potential dependence for the Faradaic efficiency of a) hydrogen evolution reaction (HER) and b) $\mathrm{CO}_{2}$ reduction reaction $\left(\mathrm{CO}_{2} \mathrm{RR}\right)$. Potential dependence of electrochemical active 
surface area normalized (ECSA) rate of c) HER and d) $\mathrm{CO}_{2} \mathrm{RR}$. All data was collected in $\mathrm{CO}_{2^{-}}$ saturated $0.1 \mathrm{M} \mathrm{NaHCO}_{3}$ electrolyte on a $\mathrm{Cu}$ foil with $67 \mu \mathrm{M} \mathrm{CTAB}$ or without CTAB.
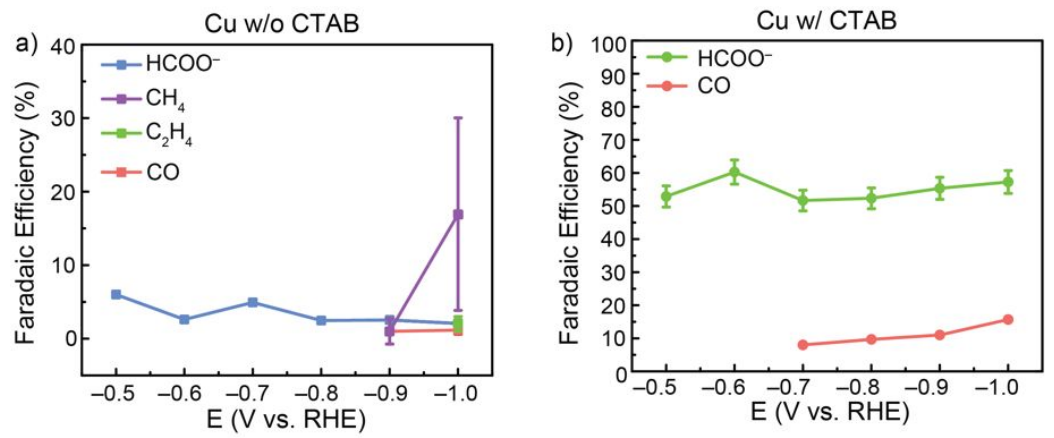

Figure S2. Faradaic efficiency of $\mathrm{Cu}$ foils with and without $67 \mu \mathrm{M} \mathrm{CTAB}$ in $\mathrm{CO}_{2}$-saturated 0.1 $\mathrm{M} \mathrm{NaHCO}_{3}$.

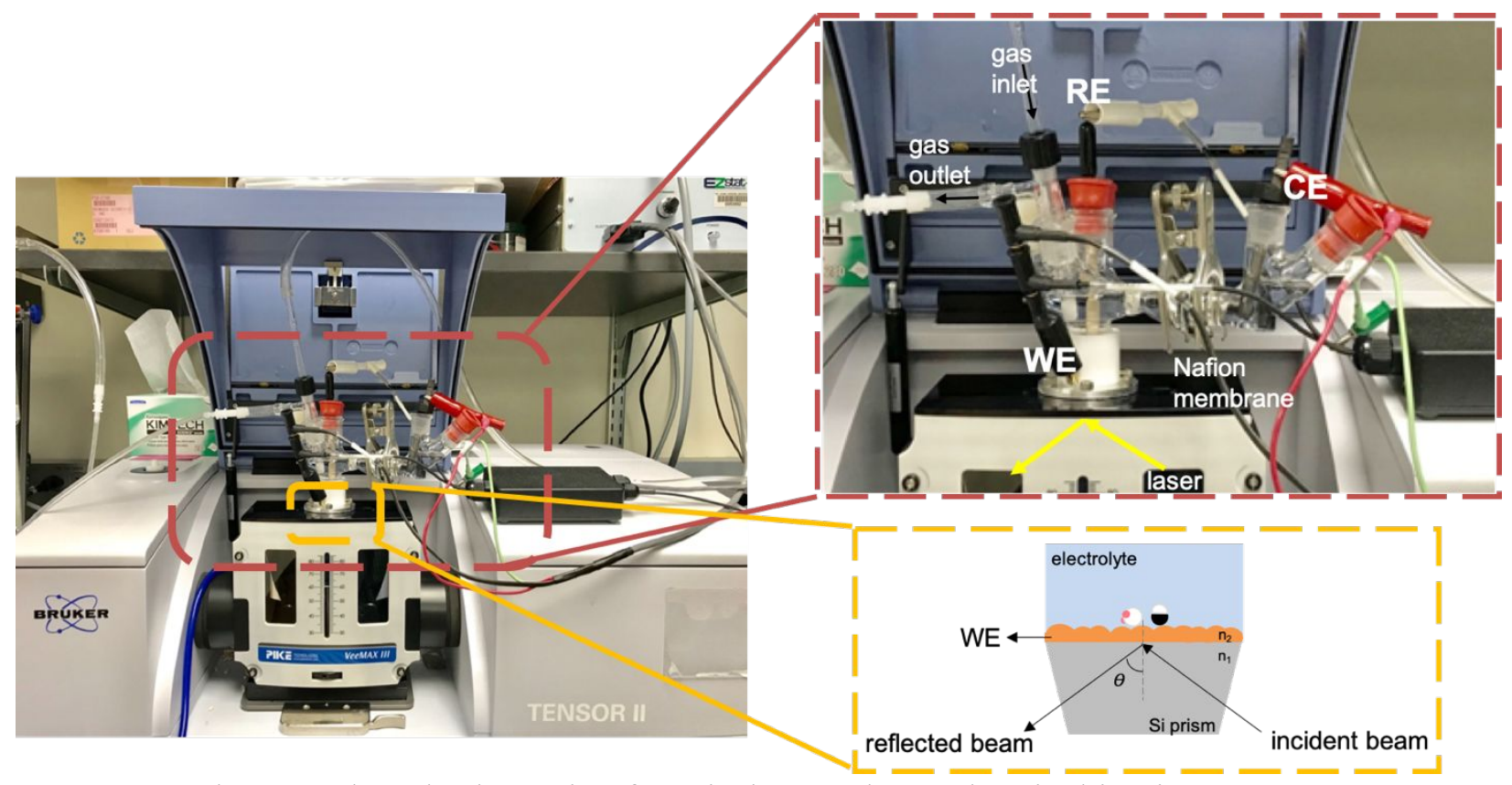

Figure S3. Photograph and schematic of our in-house electrochemical in-situ FTIR setup. 


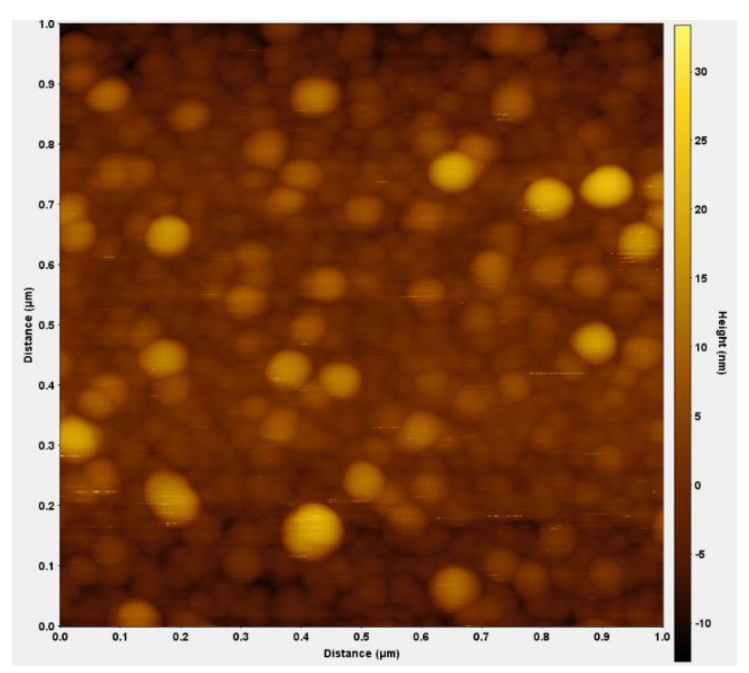

Figure S4. Atomic force microscopy (AFM) image of evaporated $\mathrm{Cu}$ on $\mathrm{Si}$.

a)

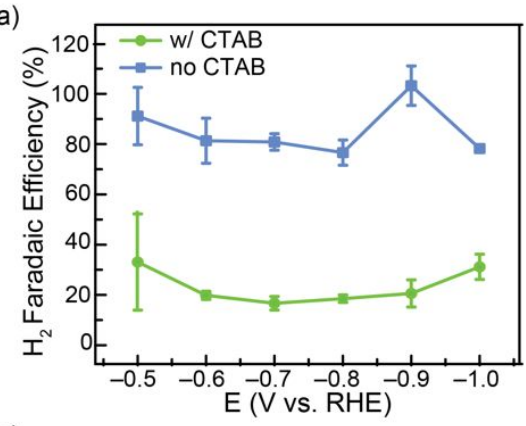

c)
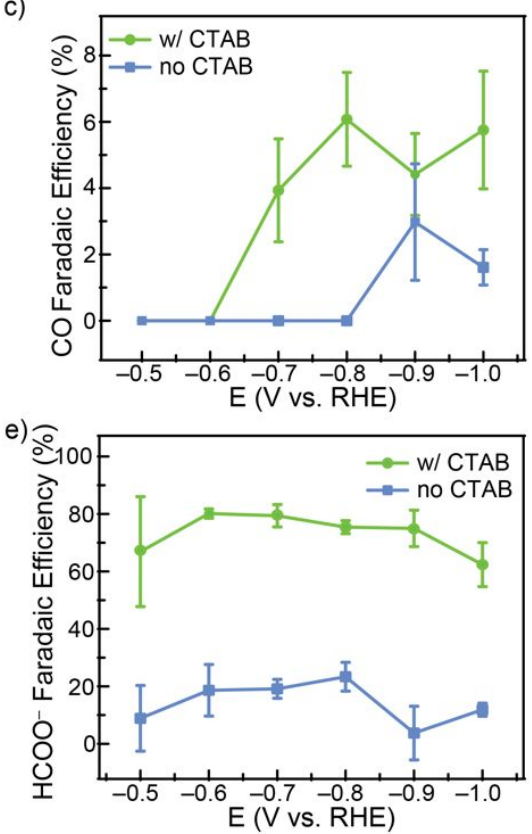

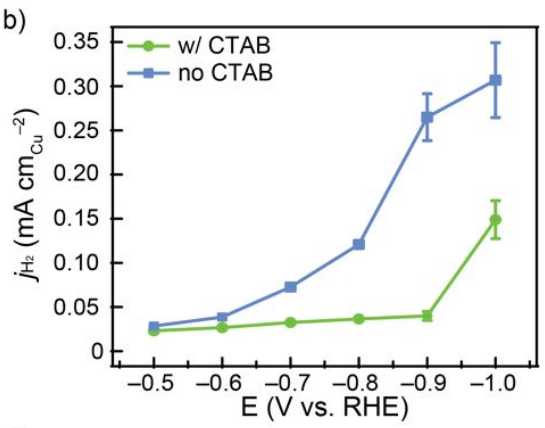

d)

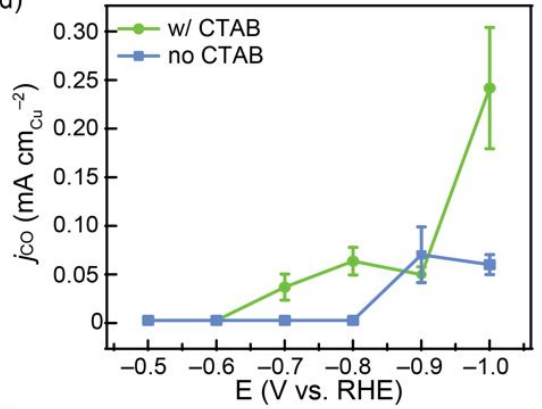

f)

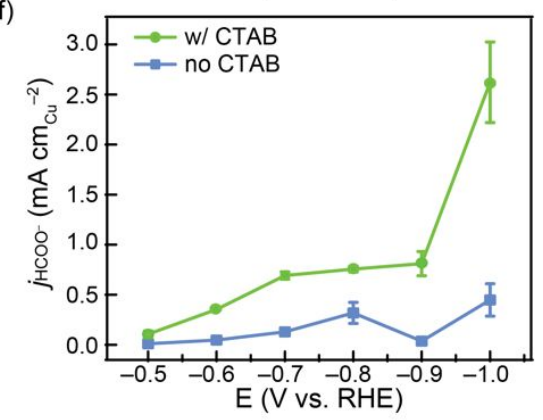

Figure S5. Faradaic efficiency and partial current densities of $\mathrm{Cu}$-coated $\mathrm{Si}$ with and without 67 $\mu \mathrm{M} \mathrm{CTAB}$ in $\mathrm{CO}_{2}$-saturated $0.1 \mathrm{M} \mathrm{NaHCO}_{3}$. 

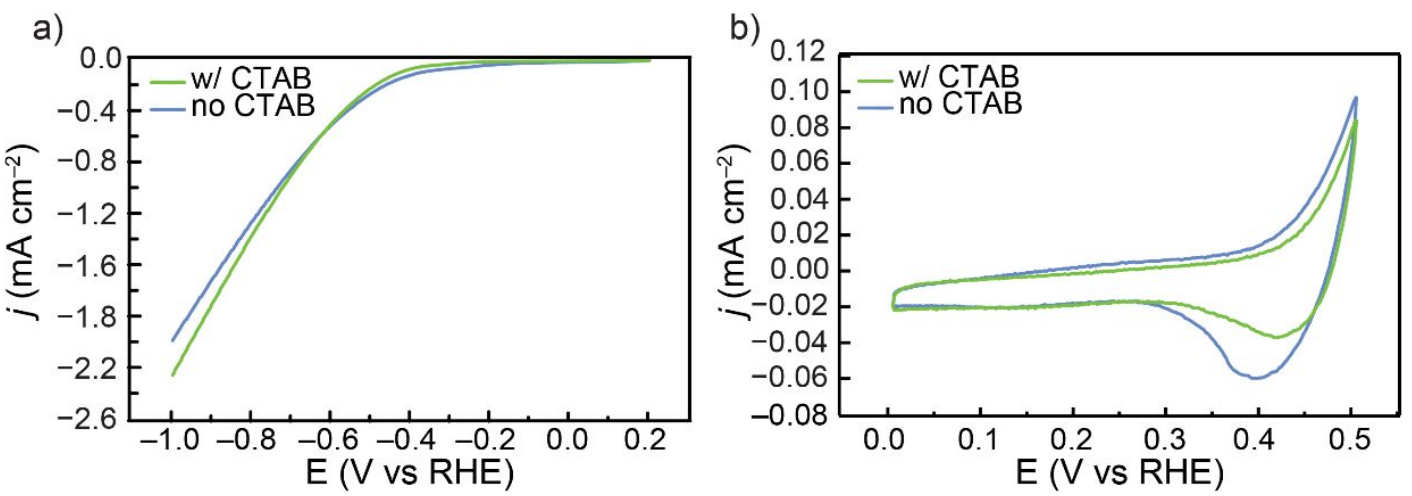

Figure S6. a) Linear sweep voltammogram, and b) Cyclic voltammogram (CV) of Cu-coated Si prism with and without $67 \mu \mathrm{M} \mathrm{CTAB}$ in $\mathrm{CO}_{2}$-saturated $0.1 \mathrm{M} \mathrm{NaHCO}_{3}$. The $\mathrm{CV}$ of $\mathrm{Cu}$ show that the surfaces are the same.
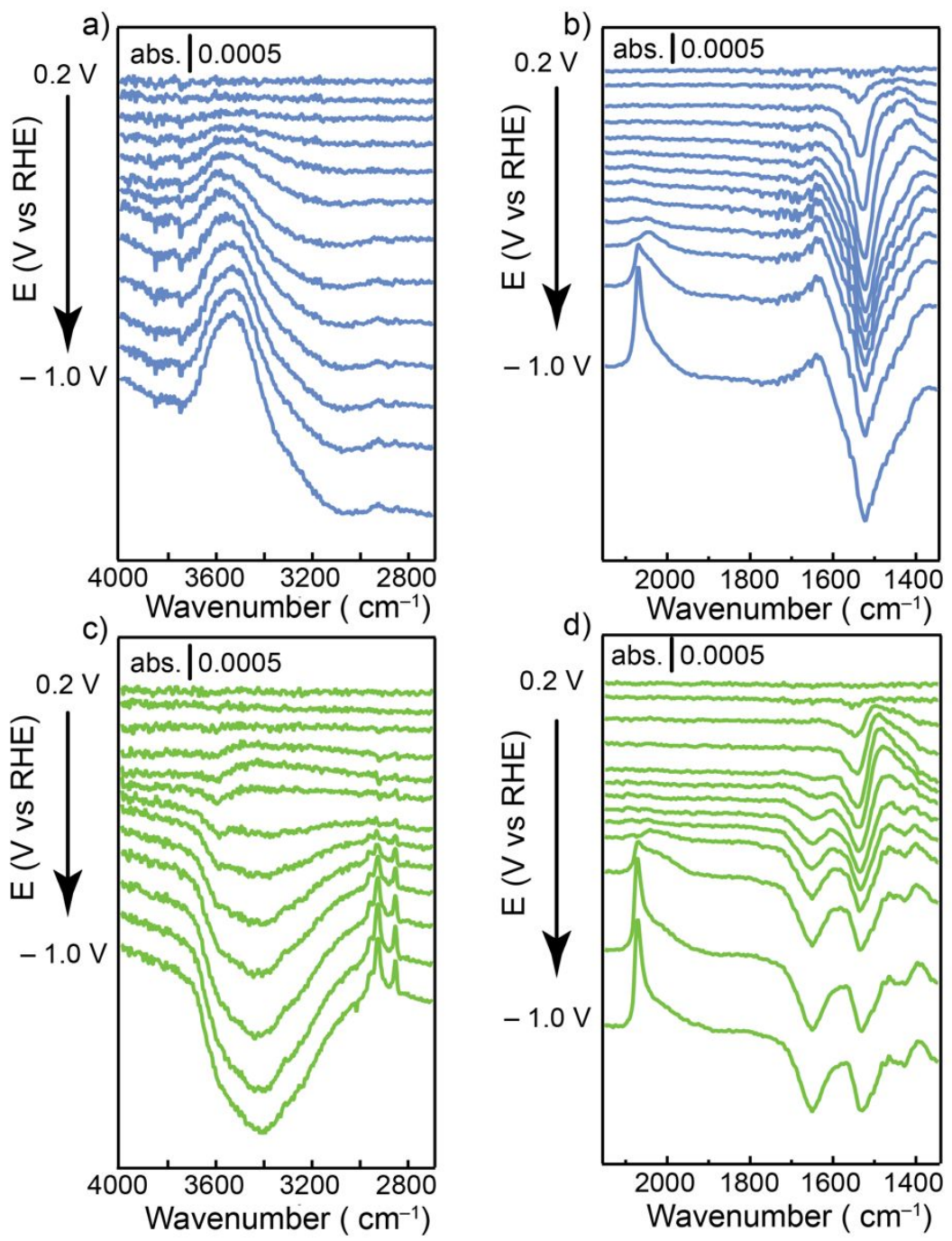

Figure S7. Additional infrared spectra demonstrating reproducibility. a) v-OH vibrational region of $\mathrm{H}_{2} \mathrm{O}$, and b) $\mathrm{CO}, \delta_{\mathrm{HOH}}$, and $\mathrm{OCO}$ vibration of (bi)carbonate in $\mathrm{CO}_{2}$-saturated $0.1 \mathrm{M} \mathrm{NaHCO}_{3}$, 
c) $v-\mathrm{OH}$ vibrational region of $\mathrm{H}_{2} \mathrm{O}$ and $\mathrm{C}-\mathrm{H}$ vibrational bands of $\mathrm{CTAB}$, d) $\mathrm{CO}, \delta_{\mathrm{HOH}}$, and $\mathrm{OCO}$ vibration of (bi)carbonate in $\mathrm{CO}_{2}$-saturated $0.1 \mathrm{M} \mathrm{NaHCO}_{3}+67 \mu \mathrm{M} \mathrm{CTAB}$. All data was collected during a linear sweep voltammogram at $10 \mathrm{mV} \mathrm{s}^{-1}$ scan rate.

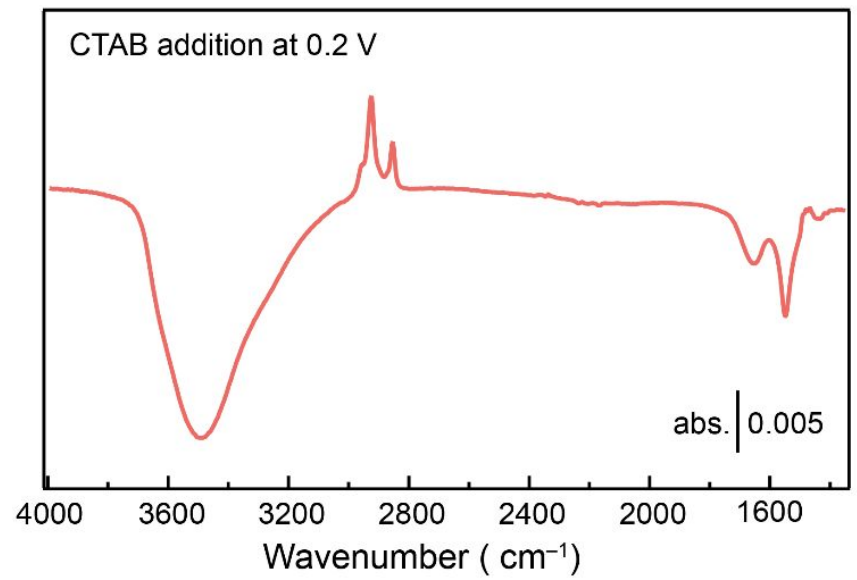

Figure S8. Infrared spectrum to indicate CTAB addition at $0.2 \mathrm{~V}$ vs RHE. Sample spectrum collected in $\mathrm{CO}_{2}$-saturated $0.1 \mathrm{M} \mathrm{NaHCO}_{3}+67 \mathrm{uM} \mathrm{CTAB}$, reference spectrum collected in $\mathrm{CO}_{2}$ saturated $0.1 \mathrm{M} \mathrm{NaHCO}$.
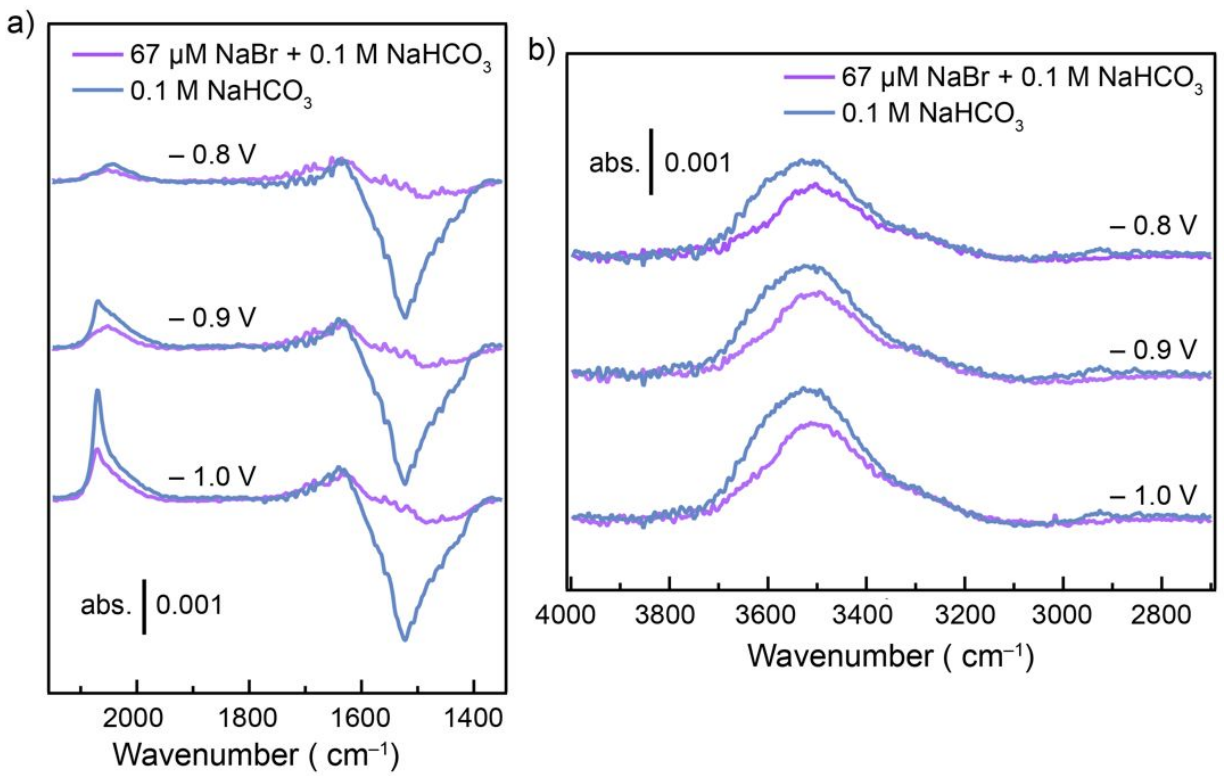

Figure S9 Comparison of spectra collected on $\mathrm{Cu}$-coated $\mathrm{Si}$ with and without $67 \mu \mathrm{M} \mathrm{NaBr}$ in $\mathrm{CO}_{2}$ saturated $0.1 \mathrm{M} \mathrm{NaHCO}_{3}$. 

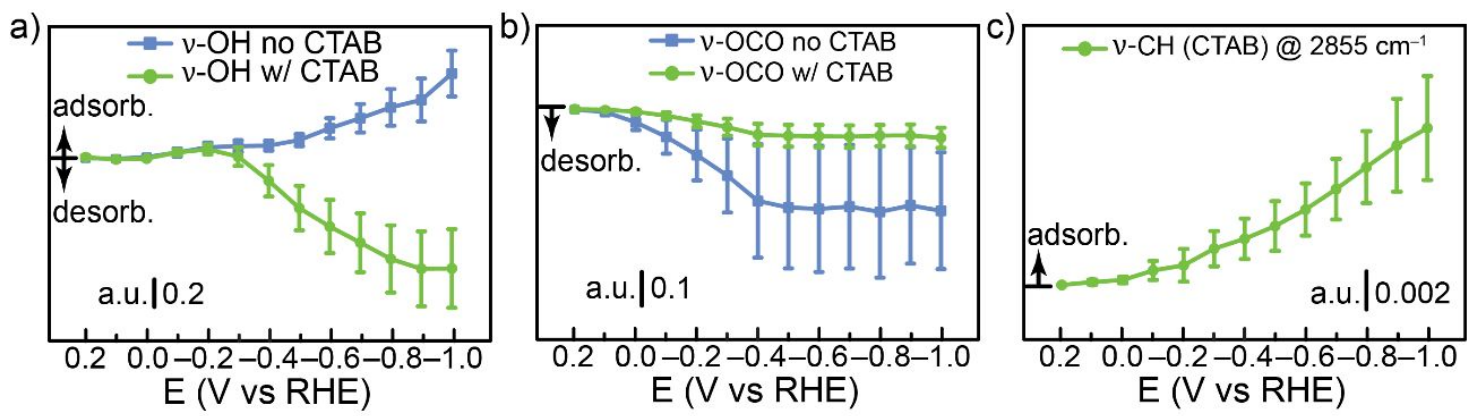

Figure S10. Integrated band intensity with error bars calculated from three individual samples of a) $\mathrm{v}-\mathrm{OH}$ region, b) OCO band of (bi)carbonate and formate, c) C-H bands of CTAB collected during a cathodic linear sweep voltammogram at $10 \mathrm{mV} \mathrm{s}^{-1}$ scan rate in $\mathrm{CO}_{2}$-saturated $0.1 \mathrm{M}$ $\mathrm{NaHCO}_{3}$ electrolyte.

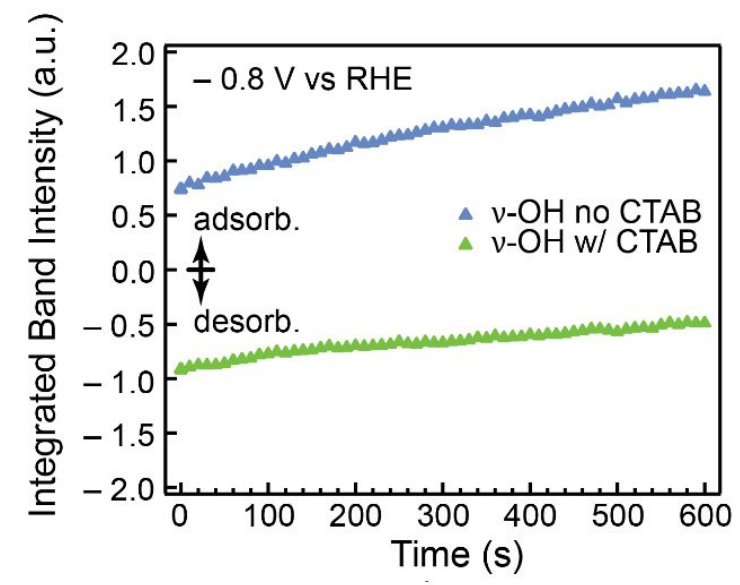

Figure S11. Time dependence of the $v-\mathrm{OH}$ band on $\mathrm{Cu}$-coated $\mathrm{Si}$ with and without $67 \mu \mathrm{M} \mathrm{CTAB}$ in $\mathrm{CO}_{2}$-saturated $0.1 \mathrm{M} \mathrm{NaHCO}_{3}$ at $-0.8 \mathrm{~V}$ vs RHE. 

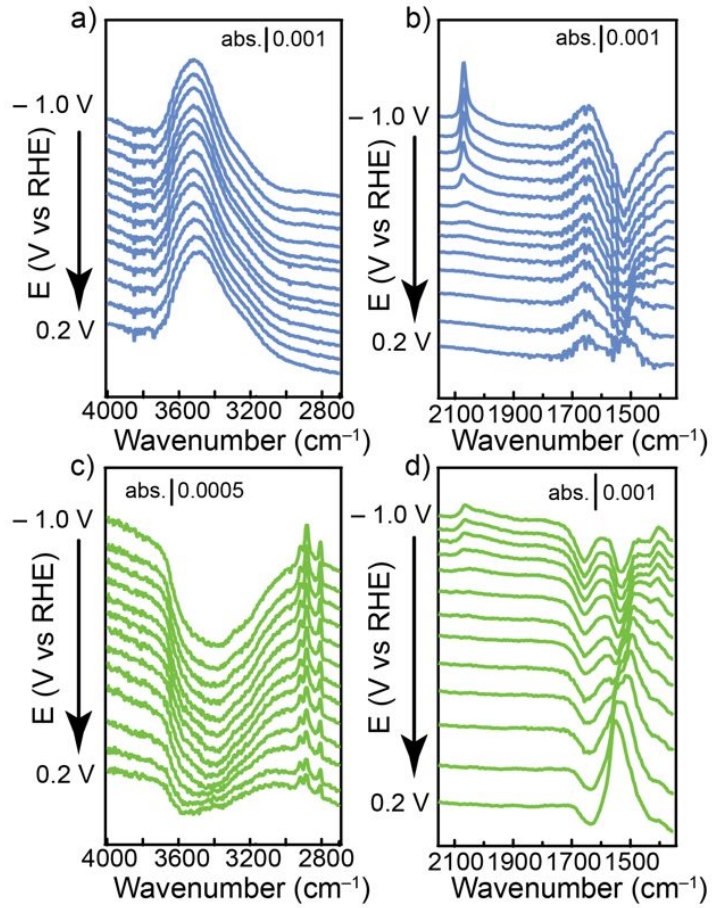

Figure S12. Infrared spectra in anodic scan. a) $v-\mathrm{OH}$ vibrational region of $\mathrm{H}_{2} \mathrm{O}$, and b) $\mathrm{CO}, \delta_{\mathrm{HOH}}$, and $\mathrm{OCO}$ vibration of (bi)carbonate in $\mathrm{CO}_{2}$-saturated $0.1 \mathrm{M} \mathrm{NaHCO}_{3}, \mathrm{c}$ ) v-OH vibrational region of $\mathrm{H}_{2} \mathrm{O}$ and $\mathrm{C}-\mathrm{H}$ vibrational bands of $\left.\mathrm{CTAB}, \mathrm{d}\right) \mathrm{CO}, \delta_{\mathrm{HOH}}$, and $\mathrm{OCO}$ vibration of (bi)carbonate in $\mathrm{CO}_{2}$-saturated $0.1 \mathrm{M} \mathrm{NaHCO}_{3}+67 \mu \mathrm{M}$ CTAB. All data was collected during a linear sweep voltammogram at $10 \mathrm{mV} \mathrm{s}^{-1}$ scan rate.
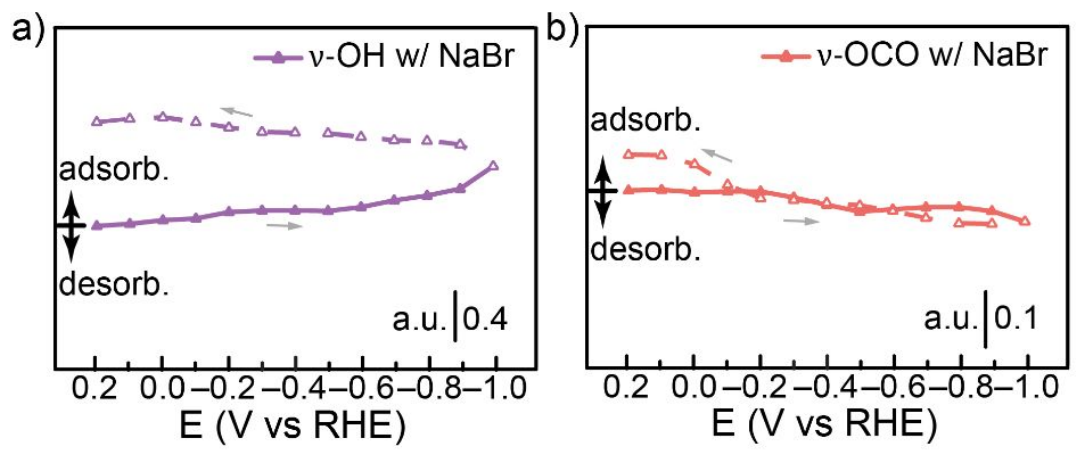

Figure S13. a) v-OH and b) v-OCO adsorption profiles in $\mathrm{CO}_{2}$-saturated $0.1 \mathrm{M} \mathrm{NaHCO}_{3}+67$ $\mathrm{uM} \mathrm{NaBr}$. 


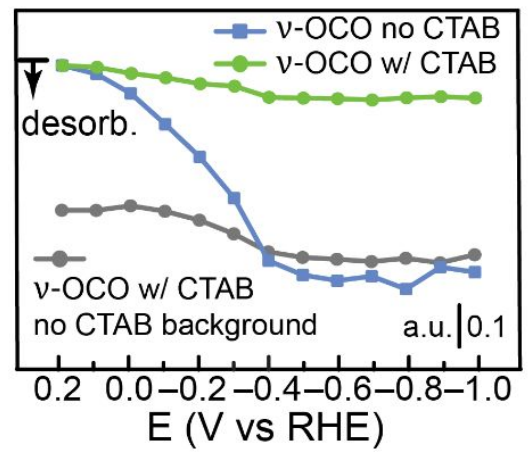

Figure S14. Integrated band intensity of $v-\mathrm{OCO}$ band of (bi)carbonate and formate, collected during a linear sweep voltammogram (from 0.2 to $-1.0 \mathrm{~V}$ ) at $10 \mathrm{mV} / \mathrm{s}$ scan rate in $\mathrm{CO}_{2}$-saturated $0.1 \mathrm{M} \mathrm{NaHCO}$ electrolyte with (green trace) and without $67 \mu \mathrm{M}$ of CTAB (blue trace). Background spectrum was collected at $0.2 \mathrm{~V}$ vs RHE the respective solutions, except for the spectrum shown in dark grey, which was backgrounded to CTAB-free electrolytes.

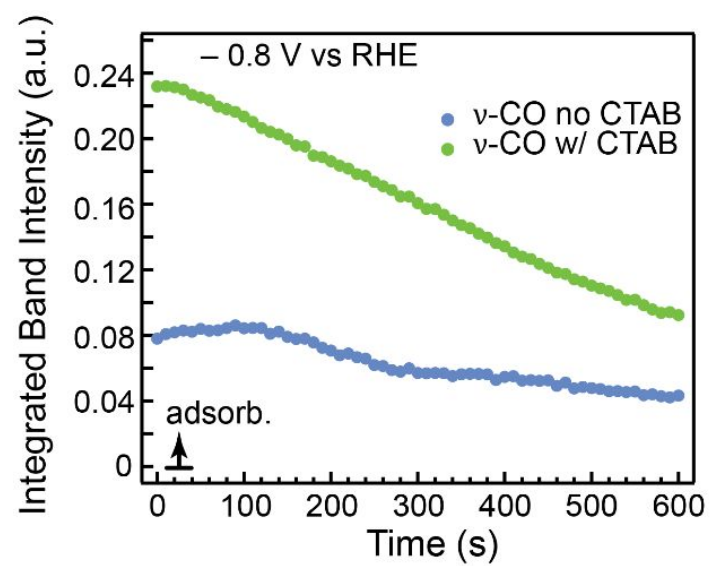

Figure S15. Time dependence of the $v$-CO band on $\mathrm{Cu}$-coated $\mathrm{Si}$ with and without $67 \mu \mathrm{M} \mathrm{CTAB}$ in $\mathrm{CO}_{2}$-saturated $0.1 \mathrm{M} \mathrm{NaHCO}_{3}$ at $-0.8 \mathrm{~V}$ vs RHE. 